\section{Immune Thrombocytopenic Purpura with Acute Lymphoblastic Leukemia- An Unusual Association}

Hematologic malignancies such as Hodgkins lymphoma, Non-Hodgkin lymphoma and chronic lymphocytic leukemia have been associated with immune thrombocytopenic purpura (ITP) but it is rare to see ITP in patient with acute lymphoblastic leukemia (ALL) $[1,2]$. ALL is a immunosuppressive disease and chemotherapy results in further immunosuppressive state. Therefore, association of autoimmune diseases with ALL is rare. Nine cases of ITP in children with ALL have been reported so far, three of them were acute ITP, and rest were chronic ITP [3]. Only one such case has been reported from India [4].

A 15-year-old girl was admitted to us with fever, increasing pallor and bleeding spots over the body in July 2010. Physical examination revealed liver $5 \mathrm{~cm}$ and spleen $3 \mathrm{~cm}$ below costal margin. Complete blood count (CBC) showed hemoglobin (Hb) $6.5 \mathrm{~g} / \mathrm{dL}$, white blood cell $24000 / \mathrm{mm}^{3}$ and platelet $38,000 / \mathrm{mm}^{3}$. Peripheral blood smear showed $54 \%$ blasts. The bone marrow was consistent with pre-B ALL. Cerebrospinal fluid was negative for malignant cells. Patient was started on chemotherapy using BFM-95 regimen. Bone marrow aspiration and biopsy showed remission on the $33^{\text {rd }}$ day of treatment. After phases of Protocol-I, Protocol-M, and Protocol-II, patient was started on maintenance therapy including 6-mercaptopurine and methotrexate. After 20 months into therapy, the patient was noted to have a platelet count of $59000 / \mathrm{mm}^{3}$. Therapy was stopped for 15 days and repeat CBC showed platelet count of 38000 / $\mathrm{mm}^{3}$, a suspicion of relapse was kept and bone marrow aspiration and biopsy was performed. An adequate number of megakaryocytes with findings of ALL in remission were detected, there was nothing suggestive of myelodysplastic syndrome. The patient was started on prednisone at $2 \mathrm{mg} / \mathrm{kg}$ orally daily. After 3 weeks of prednisolone, she had improvement of her platelet count to $78000 / \mathrm{mm}^{3}$. Her last platelet count in July 2012 was $88000 / \mathrm{mm}^{3}$. Secondary causes of ITP were ruled out: antinuclear antibodies was negative, double stranded DNA was $14 \mathrm{IU} / \mathrm{mL}, \operatorname{IgG}, \operatorname{IgA}, \operatorname{IgM}$ and $\operatorname{IgE}$ were $540,35,118$ and $18 \mathrm{mg} / \mathrm{dL}$, Hepatitis B, Hepatitis C and HIV studies were negative, and anti-phospholipid antibodies (APLA) and direct coomb's test were also negative.

To conclude, the presence of thrombocytopenia in patient of ALL does not always means relapse of ALL or as a result of chemotherapy but the possibility of ITP should also be considered.

Vikas Dua and JB Sharma
ActionCancer Hospital,
Delhi, India.
drvikasdua@yahoo.com

\section{REFERENCES}

1. Carey RW, McGinnis A, Jacobson BM, Carvalho A. Idiopathic thrombocytopenic purpura complicating chronic lymphocytic leukemia. Arch Intern Med. 1976;136:62-6.

2. Ertem M, Uysal Z, Yavuz G, Gozda oglu S. Immune thrombocytopenia and hemolytic anemia as a presenting manifestation of Hodgkin disease. Pediatr Hematol Oncol. 2000;17:181-5.

3. Horino S, Rikiishi T, Niizuma H, Abe H, Watanabe Y, Onuma $\mathrm{M}$, et al. Refractory chronic immune thrombocytopenic purpura in a child with acute lymphoblastic leukemia. Int J Hematol. 2009;90:483-5.

4. Yadav SP, Chinnabhandar V. Rituximab usage in children: A double edged sword! Indian Pediatr. 2012;49:335.

\section{Hepatitis B Vaccination}

Rajasthan Government has recommended in 2011 that hepatitis $\mathrm{B}$ vaccination be given to all institutional delivered babies within $24 \mathrm{hrs}$ of birth as 0 dose so as to prevent vertical transmission. The remaining recommended doses are to be given at 6-10-14 weeks. IAP Immunization Schedule 2009-10 recommended five schedules viz. birth, 1 and 6 months; birth, 6 and 14 weeks; 6,10 and 14 weeks; birth, 6 weeks, 6 months; and birth, 6 weeks, 10 weeks, 14 weeks. The recent Consensus Recommendations of IAPCOI [1] has recommended the $0-6$ wks-6months schedule, the first dose to be administered at birth, second dose at 6 weeks and third dose at 6 months. The reason being it is more closer to immunologically ideal and most widely used 0-1-6 months schedule, and also conforms to latest ACIP recommendations wherein the final dose in the Hepatitis$B$ vaccine series should be administered no earlier than 24 weeks and at least 16 weeks after the first dose [2] .

Therefore, the question arises as to the rationality of 